\title{
Suramin inhibits wound healing following filtering procedures for glaucoma
}

\author{
Holger Mietz, Patricia Chévez-Barrios, Robert M Feldman, Michael W Lieberman
}

\begin{abstract}
Background-Trabeculectomies are the most frequently performed procedures in surgically treating eyes with glaucoma. Failures are caused by fibrosis in the external ostium of the filtering procedure. In order to inhibit the fibrotic wound healing reaction, a new pharmacological approach using suramin, which inhibits a variety of important growth factors was used.
\end{abstract}

Methods-Pigmented rabbits were used and filtering procedures performed. Suramin was applied with concentrations ranging from $10 \mathrm{mg} / \mathrm{ml}$ to $333 \mathrm{mg} / \mathrm{ml}$ once during surgery and four times following surgery. The success of the filtering procedure was assessed by intraocular pressure measurements. To evaluate possible intraocular toxic effects, treated eyes were histopathologically evaluated after 4 weeks, and the ciliary body adjacent to the site of application was examined using electron microscopy.

Results-With concentrations of suramin of $200 \mathrm{mg} / \mathrm{ml}$ and $333 \mathrm{mg} / \mathrm{ml}$, the trabeculectomies were patent longer than in the controls and in eyes operated with mitomycin $\mathrm{C}$, which currently is the most frequently used antiproliferative drug to enhance the outcome of surgery in humans. No severe toxic effects to the ciliary epithelium were seen in suramin treated eyes.

Conclusions-This study demonstrates for the first time the efficiency of a substance that broadly inhibits the action of growth factors on target cells in the setting of ocular wound healing. In this in vivo model, suramin has been shown to be highly effective in preventing scarring and in having fewer toxic side effects than usually used antimetabolites. These results therefore may suggest a new approach to the surgical treatment of glaucoma. (Br F Ophthalmol 1998;82:816-820)

Glaucomatous optic neuropathy is characterised by a typical cupping of the optic nerve head, ${ }^{12}$ and a persistent reduction of the intraocular pressure is frequently done surgically. Since the introduction of trabeculecto- mies by Cairns ${ }^{3}$ this surgical procedure has gained wide popularity among many glaucoma surgeons as the primary surgical treatment. ${ }^{4}$

Surgical failures of trabeculectomies are in most cases caused by a wound healing response at the level of the episclera and the deep fibrovascular layers of Tenon's capsule that evoke a permanent increase of outflow resistance or even complete occlusion. ${ }^{56}$ While this obstruction is less common in patients with uncomplicated primary open angle glaucoma (POAG), it is a frequent complication in patients undergoing repeated procedures or with other forms of glaucoma. The trabeculectomy success rates for POAG range from $24 \%$ to $75 \% .^{4}$

Fibroblasts have been identified as the main cell type which produce the new tissue surrounding the scleral flap ${ }^{89}$ since they play an essential role in wound healing in other locations of the body.

So far, only a few drugs have been used clinically to influence and modify the wound healing response following filtering surgery. Corticosteroids applied in the early postoperative period have an antifibroblastic potential, and their effectiveness has been shown in clinical studies. ${ }^{10}$ More potent drugs include antiproliferative substances, and 5-fluorouracil and mitomycin $\mathrm{C}$ are currently used in complicated forms of glaucoma. ${ }^{11} 12$

We report a different approach using a substance, suramin, that specifically inhibits growth factors. ${ }^{13-16}$ Suramin binds with the growth factor receptors and therefore inhibits binding of the growth factors to the target cells. In previous studies, we have shown that suramin delays the wound healing response in a mouse model, changes the expression and time course of growth factors in the forming scar tissue, and specifically decreases the production of collagen types I and III by ocular fibroblasts in tissue cultures at concentrations that do not affect cell viability. So far, there have been no reports about this group of drugs used to delay or inhibit ocular wound healing after glaucoma surgery.

\section{Materials and methods}

All procedures performed on animals comply with the Association for Research in Vision and Ophthalmology guidelines for the use of animals in research, and the projects were 
Table 1 Trabeculectomies performed with the adjunct of PBS (control), mitomycin $C$ (treated control), or suramin. Results show the days of failure of the surgical procedure

\begin{tabular}{|c|c|c|c|c|c|c|}
\hline \multirow[b]{2}{*}{ Group, surgery } & \multirow[b]{2}{*}{ Animals (n) } & \multirow{2}{*}{$\begin{array}{l}\text { Concentration } \\
(\mathrm{mg} / \mathrm{ml})\end{array}$} & \multirow{2}{*}{$\begin{array}{l}\text { No of } \\
\text { applications * }\end{array}$} & \multicolumn{2}{|c|}{ Time until failure (days) } & \multirow[b]{2}{*}{$p$ Value } \\
\hline & & & & Mean & SEM & \\
\hline 1 , controls & 7 & - & 0 & 4.7 & 0.5 & - \\
\hline 2, MMC & 7 & 0.5 & 1 & 8.2 & 0.5 & 0.001 \\
\hline 3, suramin & 3 & 10 & 5 & 5 & & 0.85 \\
\hline 4, suramin & 3 & 100 & 5 & 7 & & 0.001 \\
\hline 5 , suramin & 3 & 200 & 5 & 9 & & 0.001 \\
\hline 6 , suramin & 3 & 333 & 5 & 14 & & 0.001 \\
\hline
\end{tabular}

$\mathrm{MMC}=$ mitomycin $\mathrm{C}$.

^ $1=$ one application during surgery; $5=$ one application during surgery followed by subconjunctival injections for each of the next 4 days.

$\mathrm{p}$ Value $=$ Student's $t$ test for unpaired observations, compared with controls.

approved by the ethics committees of our institutions.

SURGERY

Pigmented Dutch belted female rabbits weighing $2.0-2.5 \mathrm{~kg}$ were used to study potency of the fistula in vivo. The animals were randomly divided into two groups. Only left eyes were operated. Anaesthesia was introduced by intramuscular injection of ketamine hydrochloride $(25 \mathrm{mg} / \mathrm{kg})$ and maintained by inhalation of isoflurane. A trabeculectomy as originally described by Cairns ${ }^{3}$ was performed with small variations. In brief, the conjunctiva was opened in the fornix and a limbal based conjunctival flap created. A limbal based triangular shaped scleral flap was outlined with a steel blade and carefully dissected. The anterior chamber was entered at the surgical limbus, and that area was cauterised using a thermal cauter. The patency of the opening was controlled by introduction of a small spatula through the outer opening that became readily visible in the anterior chamber. The anterior chamber remained deep in all cases, and the scleral flap was not reattached with a suture. The conjunctival incision was closed with a running 8-0 Vicryl suture. Following surgery, ointment including steroids and antibiotics (Maxitrol, Alcon) was given once into the upper and lower cul de sac.

For suramin treated animals (groups 3, 4, 5, 6) a $5 \times 5 \times 1 \mathrm{~mm}$ portion of a surgical sponge (Surgicot Comp, NC, USA; composed of compressed cellulose and cotton fibre) was placed on the sclera at the beginning of the surgery before the outlining of the scleral flap and soaked with $0.1 \mathrm{ml}$ of a special dilution of suramin for 5 minutes (Table 1). The surgery continued as in the operated controls (groups $1,2)$. On days $1,2,3$, and 4 following surgery, suramin $0.1 \mathrm{ml}$ with a similar concentration was subconjunctivally injected next to the filtering bleb. For control animals, a similar sponge soaked with phosphate buffered saline (PBS) (group 1) or mitomycin C (MMC) (group 2) was applied during surgery, and subconjunctival injections with PBS were also done during the 4 days following surgery (group 1 only).

Intraocular pressure (IOP) measurements were performed before surgery as baseline and each day after surgery using a Perkins tonometer. General anaesthesia of the animals was not performed for these measurements. The examiner was not aware of the previous treatment and surgery.

Surgical failures were defined by (i) an IOP of plus or minus $1 \mathrm{~mm} \mathrm{Hg}$ compared with baseline or (ii) an IOP difference of less than $20 \%$ compared with the unoperated fellow eye regardless of baseline values. Eyes in which surgical failures occurred within 48 hours after surgery were excluded, because it was felt that these failures were related to surgical complications and not to scarring. For evaluation, groups consisted of at least three animals each. The person who determined the day of failure was unaware of the previous treatment.

In addition, the percentage of the change from baseline IOP was determined for each animal at each day, and the mean IOP changes per group were calculated.

\section{PATHOLOGY}

Four weeks after trabeculectomy, all operated eyes were enucleated. They were bisected vertically in an anterior posterior plane, and one half was fixed in $10 \%$ formaldehyde for light microscopy using standard techniques. The second half of the globes was placed in a solution containing $1 \%$ formalin and $2.5 \%$ glutaraldehyde for electron microscopy. After fixation of at least 24 hours at $4^{\circ} \mathrm{C}$, a specimen containing superior sclera, peripheral cornea, iris, and ciliary body was excised and further processed for electron microscopic examination. Thick sections of $1 \mu \mathrm{m}$ were stained with toluidine blue for orientation, and $75 \mathrm{~nm}$ thin sections were stained with uranyl acetate and

Table 2 Mean baseline IOP values for each of the six groups (see Table 1) and the mean percentage change for each day from that baseline for the following 5-14 days

\begin{tabular}{|c|c|c|c|c|c|c|c|c|c|c|c|c|c|c|c|c|}
\hline \multirow[b]{2}{*}{ Group } & \multirow{2}{*}{$\begin{array}{l}\text { Baseline IOP } \\
(\mathrm{mm} \mathrm{Hg})\end{array}$} & \multirow[b]{2}{*}{ No } & \multicolumn{14}{|c|}{ Day following surgery/IOP change from baseline (\%) } \\
\hline & & & 1 & 2 & 3 & 4 & 5 & 6 & 7 & 8 & 9 & 10 & 11 & 12 & 13 & 14 \\
\hline 1 & 16.6 & 7 & $-39^{\star}$ & $-41^{\star}$ & $-33^{\star}$ & -17 & -14 & -4 & 0 & & & & & & & \\
\hline 2 & 16.0 & 6 & $-44^{\star}$ & $-48^{\star}$ & $-44^{\star}$ & $-44^{\star}$ & $-44^{\star}$ & $-42^{\star}$ & $-20^{\star}$ & $-21^{\star}$ & -3 & 0 & +3 & & & \\
\hline 3 & 16.0 & 2 & $-50^{\star}$ & $-44^{\star}$ & $-38^{\star}$ & $-38^{\star}$ & $0^{\star}$ & & & & & & & & & \\
\hline 4 & 16.7 & 3 & $-52^{\star}$ & $-52^{\star}$ & $-50^{\star}$ & $-44^{\star}$ & $-40^{\star}$ & $-36^{\star}$ & +1 & & & & & & & \\
\hline 5 & 16.3 & 3 & $-53^{\star}$ & $-55^{\star}$ & $-55^{\star}$ & $-55^{\star}$ & $-55^{\star}$ & $-55^{\star}$ & $-55^{\star}$ & $-55^{\star}$ & $-15^{\star}$ & -2 & -2 & & & \\
\hline 6 & 16.3 & 3 & $-55^{\star}$ & $-55^{\star}$ & $-55^{\star}$ & $-55^{\star}$ & $-55^{\star}$ & $-55^{\star}$ & $-55^{\star}$ & $-55^{\star}$ & $-37^{\star}$ & $-39^{\star}$ & $-30^{\star}$ & $-27^{\star}$ & $-27^{\star}$ & +4 \\
\hline
\end{tabular}

^Statistically significant difference from baseline (paired $t$ test, $\mathrm{p}<0.05$ ). 

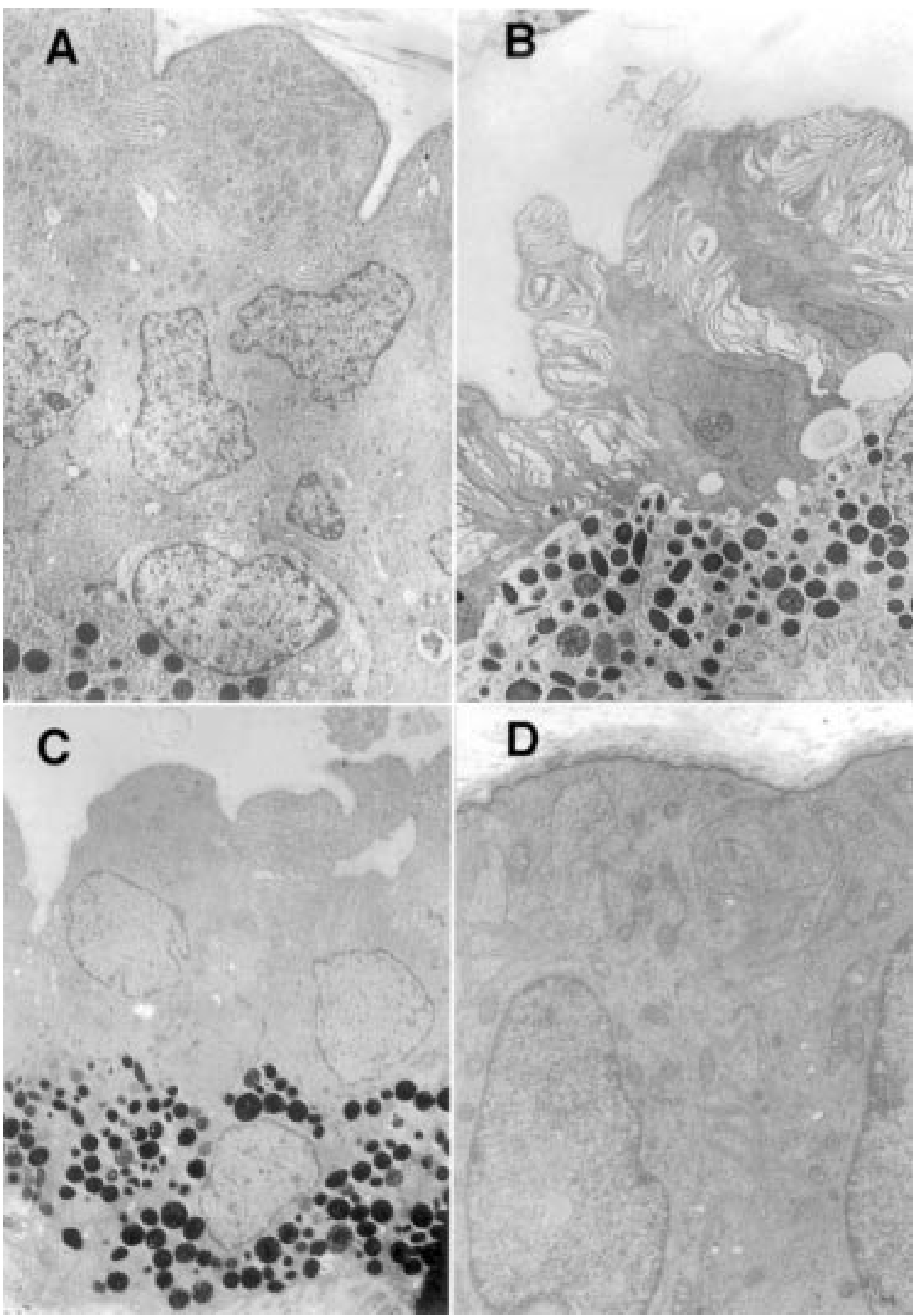

Figure 1 Electron micrograph of characteristic portions of the ciliary body epithelium of rabbit eyes 4 weeks following filtering surgery. (A) Control operated with PBS. No abnormalities are present. (B) MMC treated eye. There is

condensation of cytoplasm, irregularities of the endoplasmic reticulum, and large intra- and intercellular vacuoles. (C) (D) Eyes treated with suramin at a concentration of $333 \mathrm{mg} / \mathrm{ml}$. The structures of the cells appear intact with only small intercellular vacuoles present. The cell organelles (D) are not pathologically altered. $(A, B, C$ : original magnification, $\times 2600$; D: original magnification, $\times 5000$ ).

lead citrate and examined with a Jeol JEM 100CX (Japan) electron microscope.

\section{Results}

Control rabbits (group 1) showed closure of the filtration surgery at a mean of 4.7 days (table 1). Rabbits treated at the time of surgery with MMC (group 2) showed a mean failure time of 8.2 days $(\mathrm{p}<0.05 ; t$ test $)$.
Suramin treated animals maintained a mean failure time of 5 and 7 days when using concentrations of $10 \mathrm{mg} / \mathrm{ml}$ and $100 \mathrm{mg} / \mathrm{ml}$, respectively, which fall in the range of controls and MMC treated rabbits (groups 3, 4). With concentrations of $200 \mathrm{mg} / \mathrm{ml}$ and $333 \mathrm{mg} / \mathrm{ml}$ (groups 5,6), the mean failure time increased to 9 and 14 days, respectively, with a $p$ value of 0.001 representing an evident delay in failure 
over untreated controls and MMC treated animals (table 1). In three cases, surgical failures were seen.

A concentration response in suramin treated animals was observed in a way that higher concentrations prolonged the patency of the fistula. In a second way to interpret the data, differences of IOP values following surgery compared with baseline IOP were calculated (Table 2). The results of the duration of the patency of the fistulas were similar as determined with the first technique (table 1).

\section{PATHOLOGY}

Examination of all control, MMC, and suramin treated eyes on light microscopy did not exhibit any abnormalities. No abnormalities appeared especially in the cornea, the corneal endothelium, the ciliary epithelium, lens, retina, and sclera.

Examination of the ciliary body of the untreated control eyes by electron microscopy disclosed no pathological alterations of the ciliary epithelium (Fig 1A). The MMC treated specimens disclosed a variety of abnormalities (Fig 1B) including condensation of cytoplasm of the non-pigmented epithelial cells, marked irregularities of the cell surface, vacuoles of the endoplasmic reticulum, and vacuoles between the cell layers. Mitochondria were partially enlarged, swollen, and more variable in size and shape. Examination of suramin treated eyes (Figs 1C, D) showed no abnormalities compared with the untreated controls except for small intercellular vacuoles among nonpigmented epithelial cells in the group that was operated with the higher concentration of 333 $\mathrm{mg} / \mathrm{ml}$ of suramin. There was nothing remarkable regarding the cell membranes, the intracellular organelles, mitochondria, and endoplasmic reticulum.

\section{Discussion}

In this report, we have shown that suramin, a substance that specifically inhibits the action of growth factors in the early phase of wound healing, delays significantly the ocular wound closure in an in vivo model.

Several factors influence and control the complicated mechanism of wound healing. In the dermis, extracellular matrix components such as collagen and fibronectin, cell adhesion molecules such as selectins and integrins, and different growth factors are intimately involved with the fibroblasts. ${ }^{17}$ The importance of growth factors to initiate the various repair mechanisms has been noted in other locations. ${ }^{18-21}$ Of the many different growth factors known, TGF- $\beta 1,2$ and PDGF $A, B$ have the strongest influence on fibroblasts. ${ }^{1722}$ These growth factors increase the activity of fibroblasts and enhance the secretion of extracellular matrix components. ${ }^{17}$

Reduced levels of TGF- $\beta$ have been correlated with slowly healing wounds after burn injury $^{23}$ and with non-scarring fetal skin repair. ${ }^{18}{ }^{22}$ Likewise, decreased levels of PDGF were found in non-healing wounds in diabetic rats. ${ }^{19}$ On the other hand, elevated levels of TGF- $\beta$ are associated with increased fibrosis of several organs including heart, liver, kidney, lung, skin, and bone marrow. ${ }^{20}$ Exogenous supplementation of TGF- $\beta$ or PDGF to wounds can enhance the strength of the forming scar tissue and accelerate the healing process. ${ }^{24-26}$

In skin wounds of rats, investigators have demonstrated that levels of PDGF in the wound and forming scar tissue are elevated within the first 5 days after wounding and return to lower levels at days $10-20 .{ }^{19}$ Elevated levels for TGF- $\beta 1$ are found in pigs in the granulation tissue after experimental excisional wounding only at day 1 . TGF- $\beta 2$ in the pig model is seen from day 1 to day $7 .^{27}$

Although in humans excessive wound healing is the main cause of failures after glaucoma filtering procedures, ${ }^{5}$ this process has been studied infrequently in animal models. ${ }^{28-30}$ Animal models are different in that the created fistula usually is closed by scar tissue in the early postoperative period, while they remain patent in humans. However, in humans they may also scar early after surgery in cases of complicated glaucoma. While animals behave differently, these models have been generally accepted to study the efficacy of substances that delay wound healing. ${ }^{31} 32$ In rabbits, the created fistula closes after 5-17 days, depending on the surgical technique. On histopathological examination at different time intervals, fibroblasts proliferate from the conjunctiva into the wound and increase in number over the next days with deposition of new collagen fibres. ${ }^{29}$ Myofibroblastic proliferation was most prominent from days $7-10 .^{30}$ The wound healing processes are also similar in models using monkeys. ${ }^{32}$ The pressure lowering effect of the procedures last about 14 days. The activation of fibroblasts started as early as 24 hours after surgery and returned to normal values after 11 days when studied by autoradiography. ${ }^{8}$

Suramin was originally synthesised and designed as an antiparasitic drug and, owing to its inhibitory effect on reverse transcriptase, it has recently been introduced into clinical trials for AIDS, selected malignancies, and metastatic disease-including prostate, adrenal cortex, lymphoma, breast, and colon cancer. ${ }^{16}$ Because suramin is a heparin analogue, it binds to heparin binding proteins. The substance blocks the effects of growth factors on tumour cells in vitro and interferes with the action of growth factors by competitive binding to growth factor receptors. ${ }^{15} 16$ Growth factors inhibited include TGF- $\beta 1,2,3$, PDGF A, B, EGF, bFGF, and IGF-I, IGF-II. Therefore, cytokines that have an important effect on the stimulation of fibroblasts in wound healing are affected. In a first in vivo experiment of dermal wound healing in rats, injections of suramin caused a decrease in extracellular matrix deposition and an increase in the amount of mononuclear inflammatory cells and blood vessels in the early stages of wound healing. ${ }^{13}$

To the best of our knowledge, we have for the first time described in vivo studies which can delay the process of wound healing following glaucomatous filtering procedures using a substance that specifically inhibits the effects of growth factors. The rabbit study, which 
resembles closely the surgical procedure carried out in humans, showed that suramin has the potency to significantly delay the wound healing process in an animal model. Moreover, the effect was at least as strong as the concentration of MMC which is currently used for patient treatment. The most important aspect of this study is that suramin treated eyes did not exhibit any alterations of the ciliary epithelium. These changes are one of the most important disadvantages in the use of MMC for patients, since it has been proposed that these cellular changes contribute to the clinical phenomenon of prolonged hypotony.

In conclusion, the results of our studies suggest that suramin, a substance that influences wound healing by the blocking of several growth factor receptors on target cells, has the potential to effectively delay or inhibit the wound healing response. This substance may be useful to inhibit scarring at the site of trabeculectomies in humans for complicated and non-complicated forms of glaucoma.

Supported in part by grant ES 07827 from the National Institutes of Health; by DFG grant Mi347/4-1; by an unrestricted grant from Research to Prevent Blindness, New
York, NY; and the Hermann Eye Fund, Houston, TX, USA.

1 Quigley HA, Addicks EM, Geen WR. Optic nerve damage in human glaucoma. III. Quantitative correlation of nerve fiber loss and visual field defect in glaucoma, ischemic neuropathy, papilledema, and toxic neuropathy. Arch Ophthalmol 1982;100:135-46.

2 Hayreh SS. The 1994 von Sallman lecture. The optic nerve head circulation in health and disease. Exp Eye Res 1995;61:259-72.

3 Cairns JE. Trabeculectomy: preliminary report of a new method. Am f Ophthalmol 1968;66:673-9.

4 Nouri-Mahdavi K, Brigatti L, Weitzman M, et al. Outcomes of trabeculectomy for primary open-angle glaucoma. Ophthalmology 1995;102:1760-9.

5 Hitchings RA, Grierson I. Clinicopathological correlation in eyes with failed fistulizing surgery. Trans Ophthalmol Soc UK 1983;103:84-8.

6 Teng CC, Chi HH, Katzin HM. Histology and mechanism of filtering operations. Am f Ophthalmol 1959;47:16-34.

7 Broadway D, Hitchings R, Gierson I. Topical antiglaucomatous therapy:adverse effects on the conjunctiva and tous therapy:adverse effects on the conjunctiva and
implications for filtering surgery. F Glaucoma 1995;4:136-

8 Jampel HD, McGuigan LJB, Dunkelberger GR, et al. Cellular proliferation after experimental glaucoma filtration surgery. Arch Ophthalmol 1988;106:89-94.

9 Khaw PT, Occleston NL, Schultz G, et al. Activation and suppression of fibroblast function. Eye 1994;8:188-195.

10 Araujo SV, Spaeth GL, Roth SM, et al. A ten-year follow-up on a prospective, randomized trial of postoperative corticosteroids after trabeculectomy. Ophthalmology 1995; $102: 1753-9$

11 The Fluorouracil Filtering Study Group. Five-year follow-up of the fluorouracil filtering study group. $A m \mathcal{F}$ Ophthalmol 1996;121:349-66.

12 Palmer SS. Mitomycin as adjunct chemotherapy with trabeculectomy. Ophthalmology 1991;98:317-21.

13 Chamberlain J, Shah M, Ferguson MW. The effect of suramin on healing adult rodent dermal wounds. F Anat 1995;186:87-96.

14 Campochiaro PA, Hackett SF, Vinores SA, et al. Plateletderived growth factor is an autocrine growth stimulator in retianl pigmented epithelial cells. f Cell Sci 1994;107:245969.

15 Zumkeller W, Schofield PN. Growth factors, cytokines and soluble forms of receptor molecules in cancer patients. Anticancer Res 1995;15:344-8.

16 Stein CA. Suramin: a novel antineoplastic agent with multiple potential mechanisms of action. Cancer Res 1993;53: 2239-48.

17 Thomas DW, O'Neill ID, Harding KG, et al. Cutaneous wound healing: a current perspective. F Oral Maxillofac Surg 1995;53:442-7.

18 Lin RY, Sullivan KM, Argenta PA, et al. Exogenous transforming growth factor-beta amplifies its own expression and induces scar formation in a model of human fetal skin repair. Ann Surg 1995;222:146-54.

19 Doxey DL, Ng MC, Dill RE, et al. Platelet-derived growth factor levels in wounds of diabetic rats. Life Sci 1995;57: 1111-23.

20 Border WA, Noble NA. Transforming growth factor $\beta$ in tissue fibrosis. N Engl F Med 1994;331:1286-92.

21 Pierce GF, Tarpley JE, Tseng J, et al. Detection of plateletderived growth factor (PDGF)-AA in actively healing human wounds treated with recombinant PDGF-BB and absence of PDGF in chronic nonhealing wounds. 7 Clin Invest 1995;96:1336-50.

22 Sullivan KM, Lorenz HP, Meuli M, et al. A model of scarless human fetal wound repair is deficient in transforming growth factor beta. F Pediatr Surg 1995;30:198-203.

23 Pejnovic N, Lilic D, Zunic G, et al. Aberrant levels of cytokines within the healing wound after burn injury. Arch Surg 1995;130:999-1006.

24 Shah M, Foreman DM, Ferguson MW. Control of scarring in adult wounds by neutralising antibody to transforming growth factor $\beta$. Lancet 1992;339:213-14.

25 Murali S, Hardten DR, DeMartelaere S, et al. Effect of topically administered platelet-derived growth factor on cally administered platelet-derived growth factor
corneal wound strength. Curr Eye Res 1994;13:857-62.

26 Deuel TF, Kawahara RS. Growth factors and wound healing: platelet-derived growth factor as a model cytokine. Anпи Rev Med 1991;42:567-84.

27 Levine JH, Moses HL, Gold LI, et al. Spatial and temporal paterns of immunoreactive transforming growth factor $\beta 1$, $\beta 2$, and $\beta 3$ during excisional wound repair. Am $\mathcal{F}$ Pathol 1993;143:368-80.

28 Miller $\mathrm{MH}$, Grierson I, Unger WI, et al. Wound healing in an animal model of glaucoma fistulizing surgery in the rabbit. Ophthalmic Surg 1989;20:350-7.

29 Seetner A, Morin JD. Healing of trabeculectomies in rabbits. Can f Ophthalmol 1979;14:121-5.

30 Pfeiffer RL, Lipper S, Merritt JC, et al. Myofibroblasts in the healing of filtering wounds in rabbit, dog, and cat. Glaucoma 1981;3:277-80.

31 Rich AM, McPherson SD. Trabeculectomy in the owl monkey. Ann Ophthalmol 1973;5:1082-8.

32 Desjardins DC, Parrish RK, Folberg R, et al. Wound healing after filtering surgery in owl monkeys. Arch Ophthalmol 1986;104:1835-9. 